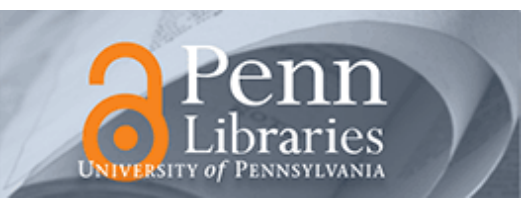

University of Pennsylvania

ScholarlyCommons

$5-27-2014$

\title{
Sleep Disturbance, Symptoms, Psychological Distress, and Health-Related Quality of Life in Pulmonary Arterial Hypertension
}

\author{
Lea Ann Matura \\ University of Pennsylvania \\ Annette McDonough \\ Alexandra L. Hanlon \\ University of Pennsylvania \\ Diane L. Carroll \\ Barbara Riegel \\ University of Pennsylvania, briegel@nursing.upenn.edu
}

Follow this and additional works at: https://repository.upenn.edu/nrs

Part of the Cardiology Commons, Cardiovascular Diseases Commons, Circulatory and Respiratory Physiology Commons, Medical Humanities Commons, Nursing Commons, and the Sleep Medicine Commons

\section{Recommended Citation}

Matura, L., McDonough, A., Hanlon, A. L., Carroll, D. L., \& Riegel, B. (2014). Sleep Disturbance, Symptoms, Psychological Distress, and Health-Related Quality of Life in Pulmonary Arterial Hypertension. European Journal of Cardiovascular Nursing, 14 (5), 423-430. http://dx.doi.org/10.1177/1474515114537951 


\title{
Sleep Disturbance, Symptoms, Psychological Distress, and Health-Related Quality of Life in Pulmonary Arterial Hypertension
}

\author{
Abstract \\ Background: \\ Pulmonary arterial hypertension (PAH) is a devastating disease characterized by elevated pulmonary \\ pressures that lead to right heart failure and premature mortality. Patients experience multiple symptoms \\ including dyspnea, fatigue and chest pain, but little is known about sleep disturbance, PAH symptoms, \\ psychological distress and health-related quality of life (HRQOL) in PAH.
}

Aim:

The purpose of this study was to describe the occurrence of sleep disturbance and compare PAH symptoms, psychological distress, and HRQOL across severity of sleep disturbance.

Methods:

One hundred and ninety-one participants completed a socio-demographic and clinical data form, PAH Symptom Severity Scale, Profile of Mood States (POMS) short form and the Medical Outcomes Short Form-36 (SF-36). Descriptive statistics were used to describe sleep disturbances; analysis of variance models were used to quantify differences in PAH symptoms, psychological distress and HRQOL by sleep disturbance groups.

Results:

The majority of participants ( $n=162,85 \%)$ were women with a mean age of 53 years. Sixty-five (34\%) reported no sleep disturbance; 54 (28\%) mild sleep disturbance; 41 (22\%) moderate sleep disturbance; and $31(16 \%)$ severe sleep disturbance. Those reporting higher sleep disturbance severity reported worse PAH symptoms, psychological distress, and HRQOL.

Conclusions:

Sleep disturbance is a significant finding in PAH. Increasing levels of sleep disturbance are associated with worse PAH symptoms, psychological states, and health-related quality of life. Interventions that decrease sleep disturbances may improve symptoms and HRQOL.

\section{Keywords}

sleep, sleep disorders, health-related quality of life, psychological states

\section{Disciplines}

Cardiology | Cardiovascular Diseases | Circulatory and Respiratory Physiology | Medical Humanities | Medicine and Health Sciences | Nursing | Sleep Medicine 
Title Page

Sleep disturbance, symptoms, psychological distress and health-related quality of life in pulmonary arterial hypertension

Author names and affiliations:

Lea Ann Matura, $\mathrm{PhD}, \mathrm{RN}^{\mathrm{a}}$

Assistant Professor

University of Pennsylvania

School of Nursing

Claire M. Fagin Hall

418 Curie Blvd., Room 322

Philadelphia, Pennsylvania 19104-4217 USA

tel: (215) 746-8819

email: matura@nursing.upenn.edu

Annette McDonough PhD, $\mathrm{RN}^{\mathrm{b}}$

Assistant Professor

University of Massachusetts

3 Solomont Way Lowell, MA 01854 USA

Phone: 1 978-934-4422

Fax: 1 978-934-2015

Annette_McDonough@uml.edu

Alexandra L Hanlon, $\mathrm{PhD}^{\mathrm{c}}$

Research Associate Professor of Nursing

University of Pennsylvania

School of Nursing

Room 479 Fagin Hall

418 Curie Blvd.

Philadelphia, Pennsylvania 19104-4217 USA

tel: (215) 898-4581

email: alhanlon@ nursing.upenn.edu

Diane L. Carroll, PhD, RN, FAAN ${ }^{\mathrm{d}}$

Yvonne L. Munn Nurse Researcher

Munn Center for Nursing Research

Institute for Patient Care

55 Fruit St

Boston, MA 02114 USA 
1 (617) 724-4934

1 (617) 724-3496 (FAX)

DCARROLL3@PARTNERS.ORG

\author{
Barbara Riegel, DNSc, RN, FAAN, FAHA ${ }^{\mathrm{e}}$ \\ Professor of Nursing, Edith Clemmer Steinbright Chair of Gerontology \\ Director, Biobehavioral Research Center \\ University of Pennsylvania School of Nursing \\ Room 335 Fagin Hall \\ 418 Curie Blvd. \\ Philadelphia, Pennsylvania 19104-4217 USA \\ tel: (215) 898-9927 \\ email: briegel@nursing.upenn.edu \\ Corresponding author: \\ Lea Ann Matura, PhD, RN \\ Assistant Professor \\ University of Pennsylvania \\ School of Nursing \\ Claire M. Fagin Hall \\ 418 Curie Blvd., Room 322 \\ Philadelphia, Pennsylvania 19104-4217 USA \\ tel: 1 (215) 746-8819 \\ email: matura@nursing.upenn.edu
}




\begin{abstract}
Background: Pulmonary arterial hypertension (PAH) is a devastating disease characterized by elevated pulmonary pressures that lead to right heart failure and premature mortality. Patients experience multiple symptoms including dyspnea, fatigue and chest pain, but little is known about sleep disturbance, PAH symptoms, psychological distress and health-related quality of life (HRQOL) in PAH.
\end{abstract}

Aim: To describe the occurrence of sleep disturbance and compare PAH symptoms, psychological distress and HRQOL across severity of sleep disturbance.

Methods: One-hundred ninety one participants completed a socio-demographic and clinical data form, PAH Symptom Severity Scale, Profile of Mood States short form (POMS) and the Medical Outcomes Short From-36 (SF-36). Descriptive statistics were used to describe sleep disturbances; analysis of variance models were used to quantify differences in PAH symptoms, psychological distress and HRQOL by sleep disturbance groups.

Results: The majority of participants $(n=162,85 \%)$ were women with a mean age of 53 years. Sixty-five (34\%) reported no sleep disturbance; 54 (28\%) mild sleep disturbance; 41 (22\%) moderate sleep disturbance; and $31(16 \%)$ severe sleep disturbance. Those with reporting higher sleep disturbance severity reported worse PAH symptoms, psychological distress and healthrelated quality of life.

Conclusions: Sleep disturbance is a significant finding in PAH. Increasing levels of sleep disturbance are associated with worse PAH symptoms, psychological states, and health-related quality of life. Interventions that decrease sleep disturbances may improve symptoms and HRQOL. 
Key Words

Sleep, sleep disorders, health-related quality of life, psychological states 


\section{Introduction}

Pulmonary arterial hypertension (PAH), one type of pulmonary hypertension, is a devastating illness affecting primarily young to middle-aged women. PAH is defined hemodynamically as a mean pulmonary arterial pressure $\geq 25 \mathrm{mmHg}$ and a pulmonary capillary wedge pressure $<15 \mathrm{mmHg}$.(1) Overtime, these elevated pulmonary pressures lead to right heart failure. The etiology of PAH includes idiopathic, familial, connective tissue disease, portopulmonary hypertension, sickle cell disease and congenital heart disease. Approximately $80 \%$ of those diagnosed with PAH are women. The mean age at diagnosis is 50 years,(2) although there is typically a delay of 2 years from symptom onset to diagnosis.(3) Estimated prevalence of PAH is 7.6 to 15 cases per million. $(4,5)$ Symptoms of PAH include fatigue and dyspnea on exertion that may be attributed to other cardiopulmonary disorders. Mortality remains high; $61 \%$ at 5 years. $(6,7)$

Recent studies show patients with PAH experience multiple symptoms that interfere with their lives and negatively affect their quality of life.(7-9) Sleep disturbance is increasingly recognized as a factor interfering with the ability to cope with symptoms and maintain healthrelated quality of life (HRQOL).(10) Only two studies investigating sleep disturbance in pulmonary hypertension have been conducted and these studies illustrate that sleep disturbances may be a factor greatly interfering with the HRQOL of these patients. $(10,11)$ Sleep disturbance in PAH can be caused by insomnia and restless leg syndrome. Seventy-three percent of patients $(\mathrm{N}=40)$ with pulmonary hypertension had poor sleep quality that was associated with depression, dyspnea and decreased HRQOL.(10) Fifty percent had insomnia, 26\% reported excessive daytime sleepiness (EDS) and 30\% were found to have restless leg syndrome. Prostanoid therapy was associated with improved HRQOL but not sleep quality.(10) In another study $46 \%(\mathrm{~N}=55)$ 
of those with pulmonary hypertension had restless leg syndrome.(11) Those with a history of hypothyroidism and opioid use for leg pain were most likely to have restless leg syndrome. Limitations of these studies included small sample sizes and inclusion of various etiologies of pulmonary hypertension, making it difficult to generalize to those with PAH only.

These preliminary studies suggest sleep disturbance is present in pulmonary hypertension, but the prevalence of sleep disturbance in those with PAH only remains unknown. Understanding the effects of sleep disturbance in patients with PAH may have implications for interventions and patient outcomes such as morbidity, psychological distress and HRQOL. The aims of this study were to:

(1) describe the occurrence of sleep disturbance and

(2) compare PAH symptom, psychological distress and HRQOL across severity of sleep disturbance.

Methods

Study Design

A cross-sectional study design was used.

Sample

The convenience sample included 191 participants recruited from United States PAH support groups, an on-line Pulmonary Hypertension Association (PHA) discussion board, and at Northeast United States and international Pulmonary Hypertension conferences. The PHA sponsors a biennial conference where investigators can recruit and enroll study participants. At a monthly support meeting the principal investigator (PI) was introduced and allowed to briefly 
discuss the purpose of this study and invite participants to approach the PI after the meeting if they wished to participate. An advertisement was posted by the PHA website administrator; participants contacted the PI via email if they were interested in participating. Only those patients self-reporting PAH who were able to read and speak English were included. Patients were enrolled over an 18 month period.

Measures

Participants completed the following questionnaires: a socio-demographic and clinical data form, the PAH Symptom Severity Scale, the Profile of Mood States (POMS) short form the Medical Outcomes Study Short Form- 36 (SF-36).

Socio-demographic and Clinical Data Form: Socio-demographic and clinical variables were collected via a tool developed by the research team. Socio-demographic information included gender, age, ethnicity, education, occupation and employment status. Self-reported clinical variables included date of PAH diagnosis, $\mathrm{PAH}$ etiology, initial symptoms of PAH, oxygen and medication use. World Health Organization (WHO) functional class(1) was assigned by the PI (LAM) using assessment data from self-reported symptoms. WHO functional class I includes those with PAH who do not have symptoms such as shortness of breath (SOB) with exertion. Those with WHO functional class II have mild SOB with exertion while WHO functional class III patients have moderate to severe symptoms of SOB with exertion. WHO functional class IV patients have symptoms at rest.(12)

Sleep Disturbance: Sleep disturbance was measured by a single item on the PAH Symptom Severity Scale labeled "sleep difficulty". Sleep difficulty is measured on a 0 to 10 scale with zero indicating absence of sleep difficulty and 10 representing the worst possible sleep difficulty. 
PAH Symptom Severity Scale: The PAH Symptom Severity Scale is a symptom scale developed by the research team that contains 17 symptoms: SOB with exertion, SOB lying down, SOB at rest, awakening at night SOB, fatigue, sleep disturbance, chest pain, abdominal swelling, swelling of ankles and feet, syncope, palpitations, dizziness, cough, nausea, loss of appetite, hoarseness, Raynaud's phenomenon (cold, numbness of extremities). Symptoms were selected based on the literature,(13-15) input from the research team, experts caring for patients with PAH and patients with PAH. Symptoms are rated on a 0-10 scale, with zero indicating an absence of the symptom and 10 indicating "extremely intense". Participants are asked to rate their symptoms over the past month. The Cronbach alpha for the scale is typically $.90-.91 ;(7)$ in the current study alpha was .90 . Validity testing is on-going.

Psychological states The POMS short form comprised 30 items that measure fluctuating mood states. These items form six subscales anger, anxiety, depression, confusion, fatigue and vigor. Each item is rated on a 5 point Likert scale, 0 (not at all) to 4 (extremely) for each mood state. Higher scores indicate more negative moods, except vigor which is reversed scored. Concurrent validity was established using the modified Hopkins Symptom Distress Scales and Minnesota Multiphasic Personality Inventory-2.(16) Internal consistency ranges from 0.84 to $0.95 .(16,17)$ The Cronbach alpha for the current study was .70.

SF-36 The SF-36 is a widely used instrument that measures generic HRQOL. The SF-36 measures physical and mental health by assessing eight subscales. The subscales (general health, physical functioning, role physical, pain, fatigue, social functioning, mental health, role emotional) and each composite summary score (mental and physical) are reported on a scale of 0-100 with higher scores indicating better HRQOL. Validity (18) and reliability have been 
established with Cronbach alpha ranges between .73-.96.(19) The Cronbach alpha for the current study was .84 .

Procedure

This investigation conformed with the principles outlined in the Declaration of Helsinki.(20) This study was approved by the hospital and University Institutional Review Boards. Participants were given paper and pencil forms and questionnaires to complete along with a self-addressed stamped envelope. Participants were given unique identification numbers. Return of completed surveys was considered consent to participate.

\section{Statistical Analysis}

The primary outcome measure of sleep disturbance was assessed using the PAH Symptom Severity Scale. Participants were categorized into four groups on the basis of selfreported sleep disturbance: no (0) mild (1-3), moderate (4-7), and severe (8-10). These categories were established using existing literature and investigator input.(21-23) Descriptive statistics are used to characterize the population to which inferences may be made. Specifically, means and standard deviations are provided for continuous socio-demographic and clinical characteristics overall, and by sleep disturbance groups, while frequencies and percents are provided for categorical variables. Comparisons of continuous and categorical sociodemographic and clinical characteristics across groups are made using one-way Analysis of Variance (ANOVA) models and chi-square statistics, respectively. Medications are compared across groups using indicator variables for each specific medication. The total number of PAH symptoms among the sixteen symptoms examined is compared across sleep disturbance groups using a one-way ANOVA model and the F statistic, with post-hoc pair-wise comparisons 
accomplished on the basis of Dunnett's tests. Similarly, PAH symptom intensity, as well as POMS and SF-36 subscales, are described overall and within sleep disturbance groups using means and standard deviations, and compared using one-way ANOVA models and Dunnett's pair-wise post-hoc tests. No adjustment was made for multiplicity. All statistical analyses were accomplished using SPSS version 20.(24) Statistical significance was taken at the 0.05 level.

\section{Results}

Of the 191 participants, $126(66 \%)$ reported some level of sleep disturbance, Table 1. For the sleep disturbance categories, 65 (34\%) had no sleep disturbance, 54 (28\%) mild, 41 (22\%) moderate, and 31 (16\%) severe sleep disturbance. There were significant differences among the sleep disturbance groups with regards to PAH symptoms, psychological distress and HRQOL.

Table 2 provides estimates (mean \pm SD) for symptom intensity for $16 \mathrm{PAH}$ symptoms. The symptoms with the highest mean scores for the total sample were SOB with exertion and fatigue. All symptoms differed significantly between the no sleep disturbance and the severe sleep disturbance groups. Syncope did not differ among the groups. Pair-wise post-hoc differences are also indicated in Table 2. Figure 1 provides a visual display of the distribution for the total number of symptoms by each sleep disturbance group.

With regards to psychological distress, the sleep disturbance groups differed significantly on all the POMS subscales (anxiety, depression, anger, vigor, fatigue, confusion) and total score, with results for pair-wise post-hoc differences displayed in Table 3. Confusion was the only psychological state that differed between no and moderate sleep disturbance.

Similarly, the sleep disturbance groups differed significantly on all SF-36 subscales and composite summary scores (Table 4). The role emotional subscale differed only between the no 
disturbance and mild sleep disturbance and the no disturbance and severe sleep disturbance groups.

\section{Discussion}

This study demonstrates that sleep disturbance is common in PAH and associated with other PAH symptoms, psychological distress and HRQOL. As sleep disturbance severity increases, so does the occurrence of PAH symptoms and there is greater PAH symptom severity. The linear increase in symptom distress in relation to increasing sleep disturbance suggests that sleep disturbance increases with symptom severity, creating an escalating cycle of sleep disturbance and symptoms severity. Higher WHO functional classes and increased oxygen use were more common as sleep disturbance severity increased.

In our study those with worse sleep disturbance had higher PAH symptom severity and psychological distress. This is consistent with the results from a small study of patients with pulmonary hypertension where sleep quality was associated with symptoms (breathlessness, mood and energy), depression and dyspnea.(10) In patients with heart failure (HF), depression and fatigue have been associated with insomnia.(25) Additionally our study expands current knowledge of PAH symptom severity by the use of a comprehensive symptom profile. These are new findings that may provide a direction for future intervention. Perhaps screening and treating symptoms in PAH may improve sleep, but more research is necessary to test this hypothesis.

Psychological distress may be another factor explaining the occurrence of sleep disturbance. Our study shows that sleep disturbance severity was associated with anger, anxiety, depression, confusion and fatigue. Other studies have shown that depression is associated with sleep disturbance in $\mathrm{PAH}(10)$ and depression and anxiety have been found to be prevalent in 
patients with PAH.(14, 15, 26) While we do not know if sleep disturbance is the outcome of patients experiencing exacerbated symptoms and psychological distress, these findings provide us with possible directions for further investigation. For example, future research could target optimal symptom control (e.g. SOB), which could improve sleep. Conversely, improving sleep in the patient with PAH may improve their other symptoms.

Our study showed an association with PAH symptom severity and HRQOL. Similar to our findings, sleep disturbance is common in HF and impairs HRQOL. $(27,28)$ Impaired sleep and EDS affect cognition, physical functioning and treatment adherence in patients with HF.(25, 29-32) Our study showed those with worse self-reported sleep disturbance had poorer physical functioning. Insomnia symptoms are also associated with increased depression, fatigue, EDS and functional performance in HF (25) and affects global perceived health in sleep-disordered breathing.(33) Self-reported sleep quality is also associated with functional performance and mental health in HF.(34) We found those with PAH who had sleep disturbances reported higher levels of fatigue and depression.

Those with worse sleep also had lower HRQOL in our study. Physically, those with sleep disturbance also experienced fatigue and limitations in performing physical activities. Psychologically, those with sleep disturbance had psychological distress, social disability and emotional problems. A study of patients with pulmonary hypertension found sleep disturbance was associated with activity and HRQOL.(10) Those with sleep disturbance had worse physical functioning and lower mental health HRQOL. Studies have shown that insomnia (25) and sleep quality (35) are associated with functional performance in HF. More investigation is needed to determine possible underlying mechanisms of sleep disturbance than influence HRQOL in PAH. 
Sixty percent of our sample reported oxygen use and those patients tended to also have more sleep disturbance than those not reporting oxygen use Patients with obstructive sleep apnea and EDS were also found to have impaired HRQOL(36) and nocturnal oxygen desaturation was associated with HRQOL. In patients with stable HF nocturnal brain (B-type) natriuretic peptide (BNP) changes were related to the severity of night time hypoxemia but not to the type of sleep-discorded breathing episodes or arousals. No relationship was found between BNP and the frequency of sleep-disordered events. Nocturnal, intermittent hypoxemia in HF was associated with the outflow of cardiac natriuretic peptides from cardiac myocytes, suggesting that nocturnal hypoxia can increase cardiac wall stress and worsen cardiac function. The severity of hypoxemia did not correlate with increased BNP levels. Sleep-disordered breathing in patients with HF may have a negative impact due to hypoxia.(37) Similar to these studies, hypoxemia may be a contributor to sleep disturbance in PAH but more investigation is needed. We did not collect data on how patients were using their oxygen therapy (continuous, as needed, or at night only). There could be an undiagnosed sleep disorder or nocturnal hypoxemia contributing to the perception of disturbed sleep in PAH, but more investigation is needed to clarify the relationship between oxygen use and sleep disturbance.

While our study demonstrates the prevalence of sleep disturbance in patients with PAH is common, the reason for this problem remains unclear. Medications such as beta blockers have been implicated in sleep problems,(38) but were not associated with sleep disturbance in PAH, nor were angiotensin converting enzyme inhibitors (ACEI) or angiotensin receptor agonists (ARB) in the current study. This may be due to the relatively few people taking beta blockers, ACEI and ARB in this study.

\section{Limitations}


This study has several limitations. First, a non-random sample was used for this study. Self-report instruments can lead to recall bias among participants. The sleep measure was only a single item measure from the PAH Symptom Severity Scale. Single item measures have been shown to be valid and reliable in measuring other concepts such as stress, (39) and quality of life.(40) Sleep quality(41) and sleepiness(42) also have been measured using single items. This single item gives a broad but vague description of the type of sleep disturbance in PAH. We also did not measure sleep objectively using polysomnography. PAH has several etiologies, some of the subgroups have very small sample sizes, so there may be differences in how they experience symptoms, psychological distress and HRQOL. The Cronbach alpha of the POMS was borderline in this sample suggesting this may not be the best measure of psychological distress in PAH. Participants self-reported their PAH status, so we do not have verification of their diagnostic hemodynamics to verify the PAH diagnosis. Although PAH primarily affects women, men are underrepresented in this sample. Other clinical variables such as current hemodynamics were not collected and may play an important role in sleep disturbance.

\section{Conclusions}

We have established a link between difficulty sleeping and PAH symptoms, psychological distress and HRQOL in PAH. Now a follow up study is necessary to define the nature of the sleep disturbance. This study demonstrates the pervasiveness of sleep disturbance and the interplay among symptoms, psychological distress and HRQOL in patients with PAH. As we continue to describe the symptom experience in PAH, the need for comprehensive symptom assessment is needed in the clinical setting. Assessment of symptoms and sleep disturbance in PAH and implementation of interventions could improve outcomes important to patients such as symptom control, functional status and HRQOL. In addition, improvement in 
sleep and other symptoms may have an impact on hospital readmissions, morbidity and mortality outcomes but further research is needed to explore these issues.

In summary, we have demonstrated that those patients with PAH have sleep disturbance and those with increased sleep disturbance have worse PAH symptoms, psychological distress and HRQOL. Future research will need to further define sleep disturbance and underlying mechanisms along with designing and testing interventions to target sleep and symptoms. Working to improve sleep and symptoms may have an important impact on HRQOL. 


\section{Implications for Practice}

- Sleep disturbance is common in pulmonary arterial hypertension (PAH).

- Those with increasing difficulty sleeping have worse PAH symptoms and health-related quality of life.

- Screening for sleep difficulty in PAH is needed and interventions to improve sleep need to be developed and tested.

Acknowledgements

We would like to thank those who participated in this study.

Declaration of Conflicting Interests

The Authors declare that there is no conflict of interest.

Funding Acknowledgements

This work was partially supported by a Bouve College of Health Sciences, Northeastern University intramural grant and Sigma Theta Tau International Gamma Epsilon grant and the Biobehavioral Research Center, University of Pennsylvania School of Nursing. 


\section{References}

1. Galiè N, Hoeper MM, Humbert M, Torbicki A, Vachiery J-L, Barbera JA, et al. Guidelines for the diagnosis and treatment of pulmonary hypertension. European Heart Journal. 2009;30(20):2493-537.

2. Badesch DB, Raskob GE, Elliott CG, Krichman AM, Farber HW, Frost AE, et al. Pulmonary Arterial Hypertension: Baseline Characteristics From the REVEAL Registry. Chest. 2010;137(2):376-87.

3. Brown LM, Chen H, Halpern S, Taichman D, McGoon MD, Farber HW, et al. Delay in Recognition of Pulmonary Arterial Hypertension. Chest. 2011;140(1):19-26.

4. Humbert M, Sitbon O, Chaouat A, Bertocchi M, Habib G, Gressin V, et al. Pulmonary Arterial Hypertension in France: Results from a National Registry. Am J Respir Crit Care Med. 2006;173(9):1023-30.

5. Butrous G, Ghofrani HA, Grimminger F. Pulmonary Vascular Disease in the Developing World. Circulation. 2008;118(17):1758-66.

6. Thenappan T, Shah SJ, Rich S, Tian L, Archer SL, Gomberg-Maitland M. Survival in pulmonary arterial hypertension: a reappraisal of the NIH risk stratification equation. European Respiratory Journal. 2010;35(5):1079-87.

7. Matura L, McDonough A, Carroll D. Cluster analysis of symptoms in pulmonary arterial hypertension: a pilot study. European Journal of Cardiovascular Nursing. 2012;11(1):51-61. 
8. Matura L, McDonough A, Carroll D. Predictors of Health-Related Quality of Life in Patients With Idiopathic Pulmonary Arterial Hypertension. Journal of Hospice \& Palliative Nursing. 2012;14(4):283-92 10.1097/NJH.0b013e3182496c04.

9. McDonough A, Matura L, Carroll D. Symptom Experience of Pulmonary Arterial Hypertension Patients. Clinical Nursing Research. 2011;20(2):120-34.

10. Batal O, Khatib O, Bair N, Aboussouan L, Minai O. Sleep Quality, Depression, and Quality of Life in Patients with Pulmonary Hypertension. Lung. 2011;189(2):141-9.

11. Minai OA, Malik N, Foldvary N, Bair N, Golish JA. Prevalence and Characteristics of Restless Legs Syndrome in Patients With Pulmonary Hypertension. The Journal of Heart and Lung Transplantation. 2008;27(3):335-40.

12. Barst RJ, McGoon M, Torbicki A, Sitbon O, Krowka MJ, Olschewski H, et al. Diagnosis and differential assessment of pulmonary arterial hypertension. J Am Coll Cardiol. 2004;43(12_Suppl_S):40S-7.

13. Flattery MP, Pinson JM, Savage L, Salyer J. Living with pulmonary artery hypertension: Patients' experiences. Heart \& Lung: The Journal of Acute and Critical Care. 2005;34(2):99-107. 14. White J, Hopkins R, Glissmeyer E, Kitterman N, Elliott CG. Cognitive, emotional, and quality of life outcomes in patients with pulmonary arterial hypertension. Respiratory Research. 2006;7(1):55 .

15. Lowe B, Grafe K, Ufer C, Kroenke K, Grunig E, Herzog W, et al. Anxiety and Depression in Patients With Pulmonary Hypertension. Psychosom Med. 2004;66(6):831-6.

16. McNair DM, Lorr M, Droppleman LF, McNair DM, Lorr M, Droppleman LF. Profile of Mood States--Brief. North Tonawanda, NY: MHS/Multi-Health Systems; 2009. 
17. Lutgendorf SK, Garand L, Buckwalter KC, Reimer TT, Hong S-Y, Lubaroff DM. Life Stress, Mood Disturbance, and Elevated Interleukin-6 in Healthy Older Women. The Journals of Gerontology Series A: Biological Sciences and Medical Sciences. 1999;54(9):M434-M9.

18. McHorney CA, Ware JE, Jr., Raczek AE. The MOS 36-Item Short-Form Health Survey (SF-36): II. Psychometric and Clinical Tests of Validity in Measuring Physical and Mental Health Constructs. Medical Care. 1993;31(3):247-63.

19. Brazier JE, Harper R, Jones NM, O'Cathain A, Thomas KJ, Usherwood T, et al. Validating the SF-36 health survey questionnaire: new outcome measure for primary care. British Medical Journal. 1992;305(6846):160-4.

20. Rickham P. Human experimentation. Code of Ethics of the World Medical Association. Declaration of Helsinki. British Medical Journal. 1964;2(5402):177.

21. Chow E, Doyle M, Li K, Bradley N, Harris K, Hruby G, et al. Mild, moderate, or severe pain categorized by patients with cancer with bone metastases. Journal of palliative medicine. 2006;9(4):850-4.

22. Serlin RC, Mendoza TR, Nakamura Y, Edwards KR, Cleeland CS. When is cancer pain mild, moderate or severe? Grading pain severity by its interference with function. Pain. $1995 ; 61(2): 277-84$.

23. Given B, Given CW, Sikorskii A, Jeon S, McCorkle R, Champion V, et al. Establishing Mild, Moderate, and Severe Scores for Cancer-Related Symptoms: How Consistent and Clinically Meaningful Are Interference-Based Severity Cut-Points? Journal of Pain and Symptom Management. 2008;35(2):126-35.

24. IBM. Statistical Package for the Social Sciences (SPSS) Armonk, NY: IBM, Inc.; 2012. 
25. Redeker NS, Sangchoon J, Muench U, Campbell D, Walsleben J, Rapoport DM.

Insomnia symptoms and daytime function in stable heart failure. Sleep. 2010;33(9):1210-6.

26. McCollister DH, Beutz M, McLaughlin V, Rumsfeld J, Masoudi FA, Tripputi M, et al. Depressive Symptoms in Pulmonary Arterial Hypertension: Prevalence and Association With Functional Status. Psychosomatics. 2010;51(4):339-3398.

27. Chen H-M, Clark AP. Sleep disturbances in people living with heart failure. Journal of Cardiovascular Nursing. 2007;22(3):177-85.

28. Liu J-C, Hung H-L, Shyu Y-K, Tsai P-S. The impact of sleep quality and daytime sleepiness on global quality of life in community-dwelling patients with heart failure. Journal of Cardiovascular Nursing. 2011;26(2):99-105.

29. Riegel B, Moelter ST, Ratcliffe SJ, Pressler SJ, De Geest S, Potashnik S, et al. Excessive Daytime Sleepiness is Associated With Poor Medication Adherence in Adults With Heart Failure. Journal of Cardiac Failure. 2011;17(4):340-8.

30. Riegel B, Weaver TE. Poor sleep and impaired self-care: Towards a comprehensive model linking sleep, cognition, and heart failure outcomes. European Journal of Cardiovascular Nursing. 2009;8(5):337-44.

31. Redeker NS. Sleep Disturbance in People With Heart Failure: Implications for Self-care. Journal of Cardiovascular Nursing. 2008;23(3):231-8 10.1097/01.JCN.0000305094.20012.76.

32. Redeker NS, Muench U, Zucker MJ, Walsleben J, Gilbert M, Freudenberger R, et al. Sleep disordered breathing, daytime symptoms, and functional performance in stable heart failure. Sleep. 2010;33(4):551-60. 
33. Broström A, Strömberg A, Dahlström U, Fridlund B. Sleep difficulties, daytime sleepiness, and health-related quality of life in patients with chronic heart failure. Journal of Cardiovascular Nursing. 2004;19(4):234-42.

34. Johansson P, Alehagen U, Svensson E, Svanborg E, Dahlström U, Broström A. Determinants of global perceived health in community-dwelling elderly screened for heart failure and sleep-disordered breathing. Journal of Cardiovascular Nursing. 2010;25(5):E16-E26. 35. Redeker NS, Hilkert R. Sleep and Quality of Life in Stable Heart Failure. Journal of Cardiac Failure. 2005;11(9):700-4.

36. Martínez-García MA, Soler-Cataluña JJ, Román-Sánchez P, González V, Amorós C, Montserrat JM. Obstructive sleep apnea has little impact on quality of life in the elderly. Sleep Medicine. 2009;10(1):104-11.

37. Gottlieb JD, Schwartz AR, Marshall J, Ouyang P, Kern L, Shetty V, et al. Hypoxia, Not the Frequency of Sleep Apnea, Induces Acute Hemodynamic Stress in Patients With Chronic Heart Failure. Journal of the American College of Cardiology. 2009;54(18):1706-12.

38. Yilmaz M, Erdem A, Yalta K, Turgut O, Yilmaz A, Tandogan I. Impact of beta-blockers on sleep in patients with mild hypertension: a randomized trial between nebivolol and metoprolol. Adv Therapy. 2008;25(9):871-83.

39. Aaronson NK, Ahmedzai S, Bergman B, Bullinger M, Cull A, Duez NJ, et al. The European Organization for Research and Treatment of Cancer QLQ-C30: a quality-of-life instrument for use in international clinical trials in oncology. Journal of the National Cancer Institute. 1993;85(5):365-76. 
40. Yohannes AM, Dodd M, Morris J, Webb K. Reliability and validity of a single item measure of quality of life scale for adult patients with cystic fibrosis. Health and Quality of Life Outcomes. 2011;9(1):1-8.

41. Cappelleri JC, Bushmakin AG, McDermott AM, Sadosky AB, Petrie CD, Martin S. Psychometric properties of a single-item scale to assess sleep quality among individuals with fibromyalgia. Health Qual Life Outcomes. 2009;7:54.

42. Riegel B, Hanlon AL, Zhang X, Fleck D, Sayers SL, Goldberg LR, et al. What is the best measure of daytime sleepiness in adults with heart failure? Journal of the American Association of Nurse Practitioners. 2013;25(5):272-9. 
Table 1. Socio-demographic and clinical characteristics for the total sample of adults with Pulmonary Arterial Hypertension and separated by sleep disturbance category

\begin{tabular}{|c|c|c|c|c|c|c|}
\hline Variable $(\mathrm{N}=191)$ & $\begin{array}{l}\text { Total } \\
\mathrm{N}=191\end{array}$ & $\begin{array}{l}\text { No Sleep } \\
\text { Disturbance } \\
n=65\end{array}$ & $\begin{array}{l}\text { Mild Sleep } \\
\text { Disturbance } \\
(\text { score } 1-3) n=54\end{array}$ & $\begin{array}{l}\text { Moderate Sleep } \\
\text { Disturbance } \\
\text { (score } 4-7) n=41\end{array}$ & $\begin{array}{l}\text { Severe Sleep } \\
\text { Disturbance } \\
(8-10) n=31\end{array}$ & $\mathrm{p}$-value \\
\hline Age (years) Mean \pm SD & $53.2 \pm 15.1$ & $53.2 \pm 16.4$ & $54.5 \pm 15.2$ & $52.7 \pm 51.2$ & $51.6 \pm 13.5$ & .853 \\
\hline Gender: female & $162(85 \%)$ & $54(83 \%)$ & $48(89 \%)$ & $32(78 \%)$ & $28(90 \%)$ & .386 \\
\hline Ethnicity: Caucasian & $168(88 \%)$ & $56(86 \%)$ & $51(94 \%)$ & $35(85 \%)$ & $26(84 \%)$ & .357 \\
\hline Marital Status: Married & $97(51 \%)$ & $26(43 \%)$ & $30(56 \%)$ & $24(59 \%)$ & $17(55 \%)$ & .474 \\
\hline Living with family/friends & $141(74 \%)$ & $18(30 \%)$ & $40(74 \%)$ & $35(85 \%)$ & $23(74 \%)$ & .161 \\
\hline College graduate & $113(59 \%)$ & $39(61 \%)$ & $36(67 \%)$ & $23(56 \%)$ & $15(48 \%)$ & .641 \\
\hline \multicolumn{7}{|l|}{ Working Status } \\
\hline Full-time & $36(19 \%)$ & $13(22 \%)$ & $9(17 \%)$ & $10(24 \%)$ & $4(13 \%)$ & .371 \\
\hline Part-time & $21(11 \%)$ & $5(8 \%)$ & $16(30 \%)$ & $6(15 \%)$ & $4(13 \%)$ & \\
\hline Retired & $43(23 \%)$ & $18(31 \%)$ & $15(28 \%)$ & $6(15 \%)$ & $4(13 \%)$ & \\
\hline Disabled & $77(43 \%)$ & $23(39 \%)$ & $21(39 \%)$ & $15(28 \%)$ & $18(58 \%)$ & \\
\hline \multicolumn{7}{|l|}{ PAH etiology } \\
\hline Idiopathic & $114(60 \%)$ & $36(55 \%)$ & $32(59 \%)$ & $27(66 \%)$ & $19(61 \%)$ & \\
\hline Autoimmune & $36(19 \%)$ & $10(15 \%)$ & $12(22 \%)$ & $5(12 \%)$ & $9(29 \%)$ & \\
\hline
\end{tabular}




\begin{tabular}{|c|c|c|c|c|c|c|}
\hline $\begin{array}{l}\text { Congenital heart disease } \\
\text { Other }\end{array}$ & $\begin{array}{l}14(7 \%) \\
27(14 \%)\end{array}$ & $\begin{array}{l}6(9 \%) \\
13(20 \%)\end{array}$ & $\begin{array}{l}3(6 \%) \\
7(13 \%)\end{array}$ & $\begin{array}{l}2(5 \%) \\
7(17 \%)\end{array}$ & \begin{tabular}{|l|}
$3(10 \%)$ \\
$0(0 \%)$
\end{tabular} & \\
\hline $\begin{array}{l}\text { WHO Functional Class } \\
\text { I } \\
\text { II } \\
\text { III } \\
\text { IV }\end{array}$ & $\begin{array}{l}22(12 \%) \\
36(19 \%) \\
54(28 \%) \\
79(41 \%)\end{array}$ & $\begin{array}{l}13(20 \%) \\
17(26 \%) \\
17(26 \%) \\
18(28 \%)\end{array}$ & $\begin{array}{l}7(13 \%) \\
9(17 \%) \\
12(22 \%) \\
26(48 \%)\end{array}$ & $\begin{array}{l}2(5 \%) \\
7(17 \%) \\
16(39 \%) \\
16(30 \%)\end{array}$ & $\begin{array}{l}0 \\
3(10 \%) \\
9(29 \%) \\
19(61 \%)\end{array}$ & .010 \\
\hline Oxygen Use & $115(60 \%)$ & $29(49 \%)$ & $37(73 \%)$ & $25(69 \%)$ & $24(77 \%)$ & .011 \\
\hline \multicolumn{7}{|l|}{ Medications } \\
\hline $\begin{array}{l}\mathrm{CCB} \\
\mathrm{ERA}\end{array}$ & $\begin{array}{l}46(24 \%) \\
95(50 \%)\end{array}$ & $\begin{array}{l}14(24 \%) \\
37(62 \%)\end{array}$ & $\begin{array}{l}14(30 \%) \\
25(52 \%)\end{array}$ & $\begin{array}{l}11(30 \%) \\
21(57 \%)\end{array}$ & $\begin{array}{l}7(24 \%) \\
12(41 \%)\end{array}$ & $\begin{array}{l}.858 \\
.328\end{array}$ \\
\hline PDE-5 & $110(58 \%)$ & $36(60 \%)$ & $34(71 \%)$ & $25(68 \%)$ & $15(52 \%)$ & .332 \\
\hline Prostanoids & $75(39 \%)$ & $29(49 \%)$ & $20(42 \%)$ & $15(41 \%)$ & $11(38 \%)$ & .771 \\
\hline Diuretics & $117(61 \%)$ & $40(67 \%)$ & $31(65 \%)$ & $23(62 \%)$ & $23(79 \%)$ & .473 \\
\hline Digoxin & $29(15 \%)$ & $8(13 \%)$ & $9(19 \%)$ & $6(16 \%)$ & $6(21 \%)$ & .808 \\
\hline Beta Blockers & $25(13 \%)$ & $10(15 \%)$ & $6(11 \%)$ & $6(15 \%)$ & $3(10 \%)$ & .828 \\
\hline
\end{tabular}




\begin{tabular}{|c|l|l|l|l|l|l|}
\hline ACEI/ARB & $23(12 \%)$ & $12(18 \%)$ & $7(13 \%)$ & $4(10 \%)$ & $0(0 \%)$ & .071 \\
\hline
\end{tabular}

$\mathrm{WHO}=$ World Health Organization; $\mathrm{CCB}=$ Calcium channel blockers; ERA= Endothelin receptor antagonists; PDE-5=

Phosphodiesterase 5-inhibitors; $\mathrm{ACEI}=$ angiotensin-converting enzyme inhibitors; $\mathrm{ARB}=$ angiotensin receptor blocker 


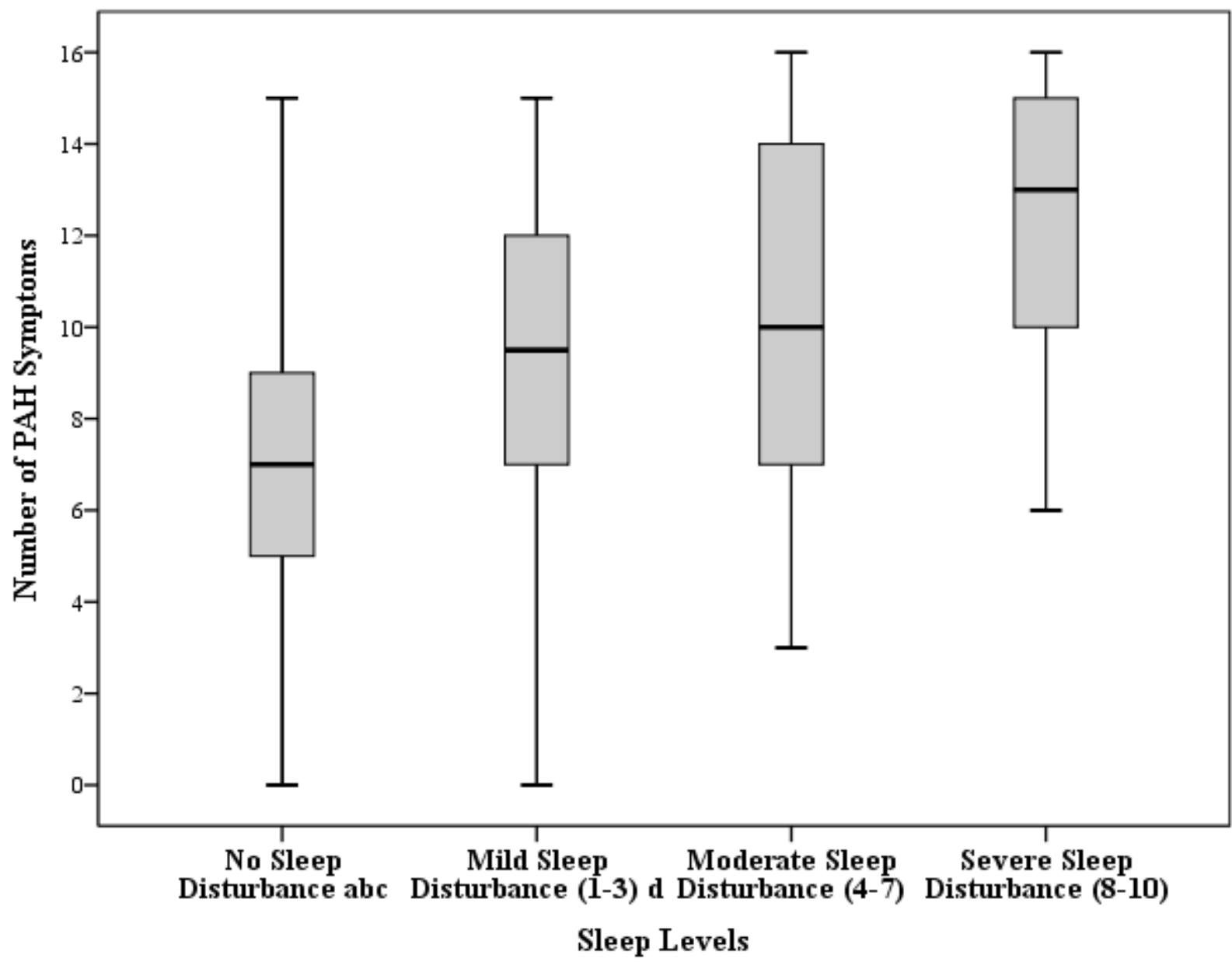

Figure 1. Pulmonary Arterial Hypertension total number of symptoms by sleep disturbance groups

a $=$ Post hoc pairwise difference $p<.05$ between no and mild sleep disturbance 
${ }^{b}=$ Post hoc pairwise difference $\mathrm{p}<.05$ between no and moderate sleep disturbance

${ }^{c}=$ Post hoc pairwise difference $\mathrm{p}<.05$ between no and severe sleep disturbance

$\mathrm{d}=$ Post hoc pairwise difference $\mathrm{p}<.05$ between mild and severe sleep disturbance 
Table 2 Pulmonary Arterial Hypertension symptom intensity (mean \pm SD) for the full sample and by sleep disturbance groups

\begin{tabular}{|c|c|c|c|c|c|c|}
\hline $\begin{array}{l}\text { Symptom Intensity } \\
\text { Mean+SD }\end{array}$ & $\begin{array}{l}\text { Total sample } \\
\mathrm{N}=191\end{array}$ & $\begin{array}{l}\text { No Sleep } \\
\text { Disturbance } \\
n=65\end{array}$ & $\begin{array}{l}\text { Mild Sleep } \\
\text { Disturbance } \\
\text { (score } 1-3) \mathrm{n}=54\end{array}$ & $\begin{array}{l}\text { Moderate Sleep } \\
\text { Disturbance } \\
(\text { score } 4-7) n=41\end{array}$ & $\begin{array}{l}\text { Severe Sleep } \\
\text { Disturbance } \\
(\text { score } 8-10) n=31\end{array}$ & p-value \\
\hline SOB with exertion ${ }^{b, c, e, f}$ & $6.2 \pm 2.7$ & $5.1 \pm 2.8$ & $6.1 \pm 2.7$ & $6.7 \pm 2.3$ & $8.1 \pm 2.0$ & $<.001$ \\
\hline Fatigue $^{\mathrm{a}, \mathrm{b}, \mathrm{c}, \mathrm{e}, \mathrm{f}}$ & $5.0 \pm 2.5$ & $3.5 \pm 2.4$ & $5.0 \pm 2.5$ & $5.8 \pm 1.9$ & $6.9 \pm 1.7$ & $<.001$ \\
\hline $\begin{array}{l}\text { Swelling of } \\
\text { ankles/feet }^{\text {bc.d,e }}\end{array}$ & $2.9 \pm 3.1$ & $1.6 \pm 2.5$ & $2.4 \pm 2.8$ & $4.1 \pm 3.0$ & $5.0 \pm 3.1$ & $<.001$ \\
\hline Palpitations ${ }^{c, e}$ & $2.9 \pm 2.6$ & $2.1 \pm 2.2$ & $2.7 \pm 2.3$ & $3.0 \pm 2.4$ & $4.7 \pm 3.3$ & $<.001$ \\
\hline Raynaud's phenomenon ${ }^{\mathrm{c}, \mathrm{e}}$ & $2.7 \pm 3.4$ & $1.5 \pm 2.6$ & $2.5 \pm 3.1$ & $3.0 \pm 3.7$ & $5.3 \pm 3.7$ & $<.001$ \\
\hline Dizziness $^{\mathrm{b}, \mathrm{c}, \mathrm{e}}$ & $2.6 \pm 2.5$ & $1.6 \pm 2.0$ & $2.2 \pm 2.2$ & $3.2 \pm 2.4$ & $5.0 \pm 2.6$ & $<.001$ \\
\hline Abdominal swelling ${ }^{\mathrm{b}, \mathrm{c}, \mathrm{e}}$ & $2.3 \pm 3.2$ & $1.0 \pm 2.2$ & $1.9 \pm 3.0$ & $3.5 \pm 3.6$ & $4.1 \pm 3.6$ & $<.001$ \\
\hline Cough $^{\mathrm{c}, \mathrm{e}}$ & $2.3 \pm 2.6$ & $1.7 \pm 2.1$ & $1.9 \pm 2.2$ & $2.8 \pm 2.7$ & $3.7 \pm 3.3$ & .001 \\
\hline Chest pain/discomfort ${ }^{\mathrm{b}, \mathrm{c}, \mathrm{e}}$ & $2.2 \pm 2.4$ & $1.3 \pm 1.7$ & $2.0 \pm 2.1$ & $2.6 \pm 2.3$ & $3.8 \pm 3.1$ & $<.001$ \\
\hline Loss of appetite ${ }^{b, c, e}$ & $1.9 \pm 2.5$ & $1.0 \pm 1.9$ & $1.3 \pm 1.7$ & $2.4 \pm 2.3$ & $4.1 \pm 3.4$ & $<.001$ \\
\hline SOB at rest ${ }^{c . e, f}$ & $1.8 \pm 2.3$ & $1.3 \pm 1.9$ & $1.5 \pm 1.8$ & $1.6 \pm 1.8$ & $3.6 \pm 3.2$ & $<.001$ \\
\hline SOB lying down ${ }^{c}$ & $1.7 \pm 2.2$ & $0.7 \pm 0.9$ & $1.6 \pm 2.0$ & $1.9 \pm 2.3$ & $3.2 \pm 3.0$ & $<.001$ \\
\hline Nausea $^{\mathrm{c}, \mathrm{e}}$ & $1.5 \pm 2.4$ & $0.7 \pm 1.6$ & $1.2 \pm 1.8$ & $1.7 \pm 2.5$ & $3.2 \pm 3.5$ & $<.001$ \\
\hline Hoarseness ${ }^{\mathrm{c}, \mathrm{e}}$ & $1.5 \pm 2.3$ & $1.1 \pm 2.1$ & $1.0 \pm 1.6$ & $1.7 \pm 2.5$ & $3.1 \pm 2.9$ & $<.001$ \\
\hline Awaken at night $\mathrm{SOB}^{\mathrm{a}, \mathrm{b}, \mathrm{c}, \mathrm{e}}$ & $0.9 \pm 1,8$ & $0.1 \pm 0.4$ & $0.7 \pm 1.4$ & $1.1 \pm 2.0$ & $2.5 \pm 2.8$ & $<.001$ \\
\hline Syncope & $0.5 \pm 1.5$ & $0.4 \pm 1.6$ & $0.3 \pm 1.1$ & $0.3 \pm 1.1$ & $1.1 \pm 2.3$ & .079 \\
\hline
\end{tabular}

Symptoms rated on 0-10 scale; 0 represents absence of the symptom; 10 represents worse possible symptom intensity. SOB=shortness

of breath; Raynaud's phenomenon= numb, painful hands or feet with cold and stress; $\mathrm{p}<.05$ after correction for significant results for multiple comparisons:

${ }^{\mathrm{a}}=$ Post hoc pairwise difference $\mathrm{p}<.05$ between no and mild sleep disturbance 
${ }^{b}=$ Post hoc pairwise difference $\mathrm{p}<.05$ between no and moderate sleep disturbance

${ }^{c}=$ Post hoc pairwise difference $\mathrm{p}<.05$ between no and severe sleep disturbance

$\mathrm{d}=$ Post hoc pairwise difference $\mathrm{p}<.05$ between mild and moderate sleep disturbance

${ }^{\mathrm{e}}=$ Post hoc pairwise difference $\mathrm{p}<.05$ between mild and severe sleep disturbance

$\mathrm{f}=$ Post hoc pairwise difference $\mathrm{p}<.05$ between moderate and severe sleep disturbance 
Table 3 Mood states in Pulmonary Arterial Hypertension (mean \pm SD) for the full sample and by sleep disturbance groups

\begin{tabular}{|c|c|c|c|c|c|c|}
\hline POMS & $\begin{array}{l}\text { Total sample } \\
\mathrm{N}=191\end{array}$ & $\begin{array}{l}\text { No Sleep } \\
\text { Disturbance } \\
n=65\end{array}$ & $\begin{array}{l}\text { Mild Sleep } \\
\text { Disturbance } \\
\text { (score } 1-3 \text { ) } \\
\mathrm{n}=54\end{array}$ & $\begin{array}{l}\text { Moderate Sleep } \\
\text { Disturbance } \\
\text { (score 4-7) } \\
\mathrm{n}=41\end{array}$ & $\begin{array}{l}\text { Severe Sleep } \\
\text { Disturbance } \\
\text { (score } 8-10 \text { ) } \\
n=31\end{array}$ & p-value \\
\hline Anxiety & $4.2 \pm 4.3$ & $2.4 \pm 2.8$ & $4.1 \pm 4.0$ & $5.4 \pm 5.1$ & $6.4 \pm 5.0$ & $<.001$ \\
\hline Depression $^{b, c}$ & $3.6 \pm 4.1$ & $2.0 \pm 2.6$ & $3.8 \pm 4.3$ & $4.3 \pm 3.8$ & $5.9 \pm 5.6$ & $<.001$ \\
\hline Anger ${ }^{b, c}$ & $3.0 \pm 3.4$ & $1.9 \pm 2.2$ & $3.3 \pm 3.6$ & $3.7 \pm 3.6$ & $4.2 \pm 4.1$ & .003 \\
\hline Vigor $^{\mathrm{a}, \mathrm{b}, \mathrm{c}}$ & $6.4 \pm 4.5$ & $8.9 \pm 4.4$ & $6.1 \pm 4.0$ & $4.5 \pm 3.9$ & $4.5 \pm 3.8$ & $<.001$ \\
\hline Fatigue $^{b, c, e, f}$ & $8.7 \pm 5.3$ & $6.0 \pm 4.5$ & $8.1 \pm 4.5$ & $10.2 \pm 4.2$ & $13.8 \pm 5.1$ & $<.001$ \\
\hline Confusion $^{b}$ & $4.7 \pm 3.2$ & $3.6 \pm 2.4$ & $4.8 \pm 3.0$ & $5.2 \pm 2.8$ & $6.0 \pm 4.7$ & .003 \\
\hline Total $^{\mathrm{a}, \mathrm{b}, \mathrm{c}, \mathrm{e}}$ & $17.5 \pm 18.8$ & $7.0 \pm 12.8$ & $16.9 \pm 16.5$ & $24.2 \pm 16.7$ & $31.8 \pm 22.6$ & $<.001$ \\
\hline
\end{tabular}

POMS=Profile of Mood States; Higher scores indicate worse mood scores, except higher vigor represents increased vigor. Total scores range from -20-100, each subscale score ranges from 0-20.; $\mathrm{p}<.05$ after correction for significant results for multiple comparisons:

${ }^{\mathrm{a}}=$ Post hoc pairwise difference $\mathrm{p}<.05$ between no and mild sleep disturbance

$\mathrm{b}=$ Post hoc pairwise difference $\mathrm{p}<.05$ between no and moderate sleep disturbance 
${ }^{c}=$ Post hoc pairwise difference $\mathrm{p}<.05$ between no and severe sleep disturbance

$\mathrm{d}=$ Post hoc pairwise difference $\mathrm{p}<.05$ between mild and moderate sleep disturbance

${ }^{\mathrm{e}}=$ Post hoc pairwise difference $\mathrm{p}<.05$ between mild and severe sleep disturbance

$\mathrm{f}=$ Post hoc pairwise difference $\mathrm{p}<.05$ between moderate and severe sleep disturbance 
Table 4. Health Status in Pulmonary Arterial Hypertension (mean \pm SD) for the full sample and by sleep groups

\begin{tabular}{|c|c|c|c|c|c|c|}
\hline $\begin{array}{l}\text { SF-36 } \\
\text { Subscale Scores }\end{array}$ & $\begin{array}{l}\text { Total sample } \\
\mathrm{N}=191\end{array}$ & $\begin{array}{l}\text { No Sleep } \\
\text { Disturbance } \\
\mathrm{n}=65\end{array}$ & $\begin{array}{l}\text { Mild Sleep } \\
\text { Disturbance } \\
\text { (score 1-3) } n=54\end{array}$ & $\begin{array}{l}\text { Moderate Sleep } \\
\text { Disturbance } \\
\text { (score } 4-7) \\
n=41\end{array}$ & $\begin{array}{l}\text { Severe Sleep } \\
\text { Disturbance } \\
\text { (score } 8-10) \\
n=31\end{array}$ & p-value \\
\hline General Health $^{\mathrm{a}, \mathrm{b}, \mathrm{c}}$ & $37.1 \pm 21.2$ & $46.1 \pm 22.8$ & $35.9 \pm 17.5$ & $31.8 \pm 19.1$ & $27.3 \pm 20.2$ & $<.001$ \\
\hline Physical function ${ }^{a, b, c}$ & $41.5 \pm 25.9$ & $52.6 \pm 27.6$ & $35.7 \pm 22.8$ & $40.1 \pm 24.5$ & $30.3 \pm 20.9$ & $<.001$ \\
\hline Role physical $^{\mathrm{a}, \mathrm{b}, \mathrm{c}}$ & $36.4 \pm 40.3$ & $56.5 \pm 41.8$ & $34.7 \pm 38.4$ & $22.8 \pm 34.0$ & $15.3 \pm 28.6$ & $<.001$ \\
\hline Pain $^{\mathrm{a}, \mathrm{b}, \mathrm{c}, \mathrm{e}}$ & $66.3 \pm 27.5$ & $82.1 \pm 21.7$ & $63.7 \pm 24.4$ & $61.1 \pm 26.0$ & $45.2 \pm 28.2$ & $<.001$ \\
\hline Vitality $^{b, c, e}$ & $41.3 \pm 22.7$ & $51.3 \pm 22.6$ & $42.0 \pm 22.7$ & $34.6 \pm 18.7$ & $27.7 \pm 18.2$ & $<.001$ \\
\hline Social function $^{\mathrm{a}, \mathrm{b}, \mathrm{c}}$ & $65.5 \pm 26.4$ & $78.7 \pm 20.3$ & $63.6 \pm 24.9$ & $54.3 \pm 28.2$ & $56.0 \pm 27.1$ & $<.001$ \\
\hline Mental health ${ }^{\mathrm{a}, \mathrm{b}, \mathrm{c}}$ & $71.9 \pm 19.3$ & $80.9 \pm 13.2$ & $70.3 \pm 20.2$ & $65.0 \pm 20.2$ & $65.1 \pm 20.5$ & $<.001$ \\
\hline Role emotional $^{\mathrm{a}, \mathrm{c}}$ & $67.0 \pm 41.5$ & $81.5 \pm 33.3$ & $57.9 \pm 42.1$ & $65.1 \pm 44.7$ & $54.8 \pm 44.4$ & .003 \\
\hline \multicolumn{7}{|l|}{$\begin{array}{l}\text { Composite Summary } \\
\text { scores }\end{array}$} \\
\hline Mental health ${ }^{\mathrm{a}, \mathrm{b}, \mathrm{c}}$ & $61.5 \pm 21.0$ & $73.1 \pm 15.3$ & $58.6 \pm 21.0$ & $54.8 \pm 20.0$ & $50.9 \pm 22.4$ & $<.001$ \\
\hline Physical health $^{\mathrm{a}, \mathrm{b}, \mathrm{c}, \mathrm{e}}$ & $45.4 \pm 22.7$ & $59.4 \pm 22.2$ & $42.4 \pm 18.2$ & $39.0 \pm 19.8$ & $29.6 \pm 18.4$ & $<.001$ \\
\hline
\end{tabular}

Higher scores indicate better health; score range 0-100; $<<.05$ after correction for significant results for multiple comparisons:

${ }^{\mathrm{a}}=$ Post hoc pairwise difference $\mathrm{p}<.05$ between no and mild sleep disturbance 
${ }^{b}=$ Post hoc pairwise difference $\mathrm{p}<.05$ between no and moderate sleep disturbance

${ }^{c}=$ Post hoc pairwise difference $\mathrm{p}<.05$ between no and severe sleep disturbance

$\mathrm{d}=$ Post hoc pairwise difference $\mathrm{p}<.05$ between mild and moderate sleep disturbance

${ }^{\mathrm{e}}=$ Post hoc pairwise difference $\mathrm{p}<.05$ between mild and severe sleep disturbance

${ }^{\mathrm{f}}=$ Post hoc pairwise difference $\mathrm{p}<.05$ between moderate and severe sleep disturbance 


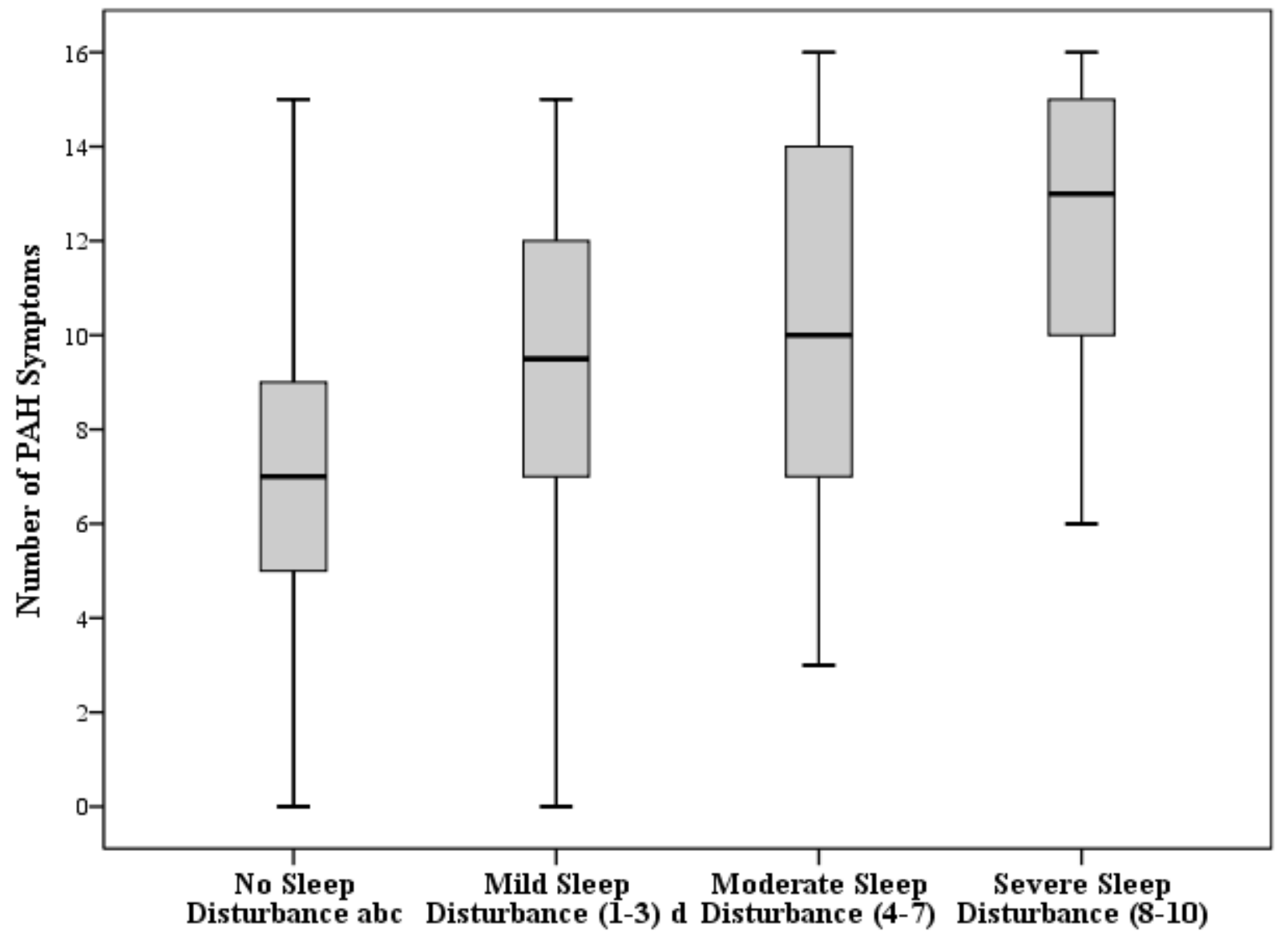

Sleep Levels 
Figure 1. Pulmonary Arterial Hypertension total number of symptoms by sleep disturbance groups

${ }^{\mathrm{a}}=$ Post hoc pairwise difference $\mathrm{p}<.05$ between no and mild sleep disturbance

$\mathrm{b}=$ Post hoc pairwise difference $\mathrm{p}<.05$ between no and moderate sleep disturbance

${ }^{c}=$ Post hoc pairwise difference $\mathrm{p}<.05$ between no and severe sleep disturbance

$\mathrm{d}=$ Post hoc pairwise difference $\mathrm{p}<.05$ between mild and severe sleep disturbance 